\title{
The Ecology Institute - its activities, prizes, funding, and staff
}

\author{
O. Kinne \\ Ecology Institute, Nordbünte 23 and 30, D-2124 Oldendorf/Luhe, Federal Republic of Germany
}

\begin{abstract}
The Ecology Institute (ECI) was founded by myself in 1984. Its facilities are situated in Oldendorf/Luhe, a small village (ca $55 \mathrm{~km}$ south of Hamburg) near the banks of the River Luhe, in the northern 'Lüneburger Heide' - a unique landscape of low human population density and large areas of nature reserves.
\end{abstract}

\section{ECI'S PRESENT ACTIVITIES AND PRIZES}

\section{Recognizing}

- the insufficient cooperation and interchange among marine, terrestrial and limnic ecologists

- the overwhelming flood of analytical research papers and the general lack of support for efforts towards critical syntheses

- the need to provide keys for opening the doors to scientific ecological information so that it becomes accessible also to non-experts and society at large

one of ECI's activities is to honor ecologists distinguished by outstanding scientific achievements who are able and willing to provide a critical synthesis and evaluation of their field of expertise, addressing an audience beyond narrow professional borderlines. In this way, ECI strives to (1) further the exchange of information between marine, terrestrial and limnic ecology; (2) compensate for the lack of balance between analyzing and synthesizing research efforts and thus help to provide more feedback and critical overview for ecological science; (3) draw the attention of scientists, administrators, politicians and the general public to important issues resulting from ecological research; (4) assist in finding a long-term compromise between the increasingly destructive potential of modern industrial societies and the need for defining and applying measures to protect nature, commensurate with achieving and sustaining the highest possible living standard for man.

Taking into account these aims, as well as his or her own field of interest, the winner of the ECOLOGY INSTITUTE PRIZE is requested to author a 200 to 300 printed-page book, to be edited by the Director and made available world-wide on a non-profit-making basis. In addition to the Prize Winner's text, the book shall contain a foreword by the Editor, a laudatio by the Chairperson of the Jury, a list of the Jury members involved in the project, and a list of ECI's staff.

While there are several international prizes offered now in ecology, the ECOLOGY INSTITUTE PRIZE is considered unique for 2 reasons: (1) it was established and is financed by research ecologists; (2) the prize gives and takes: it both honors the recipient and also requires him/her (a) to serve science which has a greater need now than ever for critical syntheses of the state of the art and for interdisciplinary cooperation, and (b) to assist administrators and politicians involved in ecology-related decision making and hence in need of definitive, first-hand scientific ecological information. The ECOLOGY INSTITUTE PRIZE is endowed with a stipend of US $\$ 5000$.

In addition to the ECOLOGY INSTITUTE PRIZE, ECI may set out a second prize honoring a young ecologist who has conducted and published uniquely independent, original and/or challenging research efforts representing an important scientific breakthrough: the IRPE PRIZE (International Recognition of Professional Excellence).

\section{PROCEDURE FOR SELECTING AND AWARDING PRIZES}

Nominations are welcome from all research ecologists. They must be addressed to the Chairperson of the ECI Jury or to ECI's Director. Forthcoming ECI Prizes will be announced world-wide in appropriate outlets (journals, society circulars, meetings, etc). Appropriate arrangements will be made by the Jury's Chairperson and/or ECI's Director.

Eligible are all ecologists engaged in scientific research, including ECI Staff members, but excluding ECI's Director. A Staff member nominated will be excluded automatically from the Jury's activities, and be replaced by another Staff member selected by the Jury's Chairperson. 
The Jury is appointed by the Director. It consists of in an annually rotating pattern -7 marine ecologists, 7 terrestrial ecologists, or 7 limnic ecologists. Jury members elect among themselves a Chairperson, and then select the Prize Winner using the nominations received, as well as their own knowledge of top performers, and their own professional judgement (i. e. a selection should not be based on merely counting the number of nominations received for a given individual).

Selection. Nominations and opinions of Jury members shall be circulated by the Chairperson among all Jury members. The final selection, which must take into account the selection criteria (p. 1), is then made after careful consideration of all material at hand and by majority vote of the Jury.

Prize awarding. The Chairperson of the Jury shall inform ECI's Director of the Jury's decision. The Director will then (a) organize procedural details for awarding the prize(s); (b) discuss - in his role as Editor contents, title etc. of the Prize Winner's book with its author.

The book authored by the Prize Winner will be published by ECI in the series 'Excellence in Ecology', and be made available world-wide at cost price.

\section{POSSIBLE FUTURE ECI ACTIVITIES}

Still being discussed among ECI staff members, 2 different categories of future activities are envisaged.

(1) Support of young ecologists. Young colleagues from countries with very limited financial resources should be enabled to travel to, and to work in, centres of scientific excellence for periods of intensive study (e. g. from 3 to $12 \mathrm{mo}$ ).

(2) Support of high-risk research. While there are a variety of financial resources available for conducting ecological research, there is little or no support for young, unusually talented researchers with bold new ideas who are able and willing to tackle venturous projects entailing high probabilities of failure. Most conventional research sponsors tend to shy away from supporting such projects, and for many young scientists the risk of failure is not acceptable in terms of establishing a professional career and of meeting social and family responsibilities. Increasing both the financial basis and the length of time of an ECI stipend beyond average levels should compensate for the increased risk involved.

We believe that there is a need for leading scientists to be in control of independent sponsor bodies such as ECI. Providing we succeed in attracting appropriate financial resources, the diversity and excellence of talents represented in ECI's staff would seem to form a most suitable medium for selecting and supporting young ecologists from poor countries and/or highly innovative, creative and audacious research projects.

I welcome additional or alternative proposals for potential future ECI activities from the international community of research ecologists.

\section{ECI'S PRESENT FUNDING}

ECI is presently funded exclusively by InterResearch, the publisher of 'Marine Ecology Progress Series' (MEPS) and 'Diseases of Aquatic Organisms' (DAO). When I founded these 2 international journals I made arrangements for channelling part of the income into setting up an institute that would honor and support excellence in ecological research, and thus serve ecological science.

It was possible to acquire small but modern and well-equipped facilities in Oldendorf/Luhe which now house both the editorial staff for the journals and the technical staff of ECI.

We hope that individuals and/or agencies sympathetic to ECI's aims may in the future support our nonprofit-making activities financially.

\section{PRIZE WINNERS $1986^{*}$}

The winner of the ECOLOGY INSTITUTE PRIZE 1986 is Profesor Tom Fenchel (Institute of Ecology and Genetics, University of Aarhus, Ny Munkegade, DK8000 Aarhus C, Denmark). His contributions to the field of marine ecology have been judged to be of the highest international calibre. Fenchel's scholarly studies on the microbial loop have directed the attention of numerous marine ecologists towards a new frontier of research. In addition, Tom Fenchel has authored several important standard publications in marine ecology. A reproduction of ECI's formal citation is shown on Fig. 1; a laudatio by the Chairman of ECI's Marine Ecology Jury follows this article.

The winner of the IRPE PRIZE 1986 is Dr. Colleen Cavanaugh (The Marine Laboratories, Harvard University, 16 Divinity Avenue, Cambridge, Massachusetts 02138, USA). Colleen Cavanaugh was awarded the IRPE PRIZE for her highly original research on chemosynthesis in sulphide-rich habitats.

\footnotetext{
- In 1987, Prize Winners will be selected in the field of terrestrial ecology. The Terrestrial Ecology Jury is presently being formed and the Chairperson will be elected shortly. Nominations for Prize Winners are invited
} 


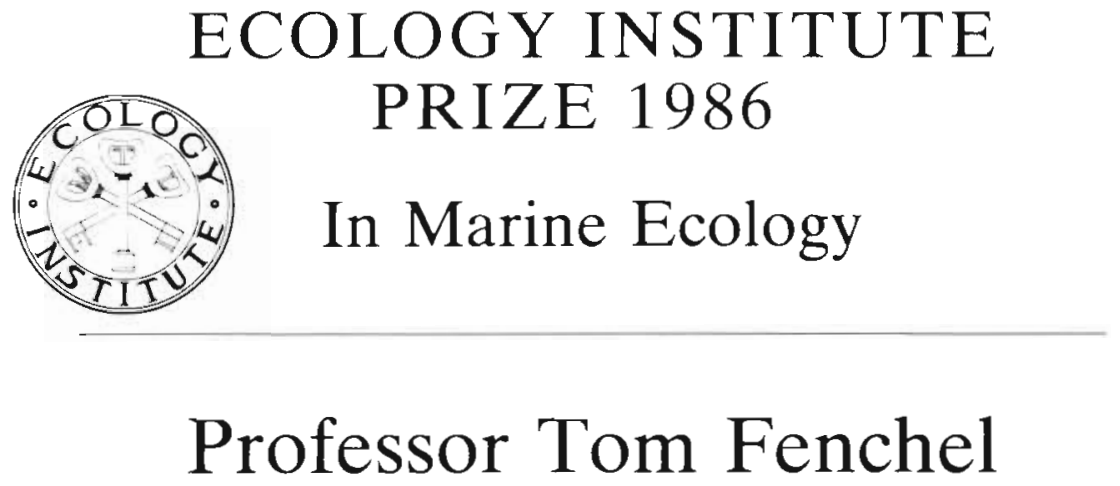

has been elected by the Marine Ecology Jury of the Ecology Institute (ECI) as the winner of the 1986

\section{ECOLOGY INSTITUTE PRIZE}

The Jury found Professor T. Fenchel's contribution to ecological knowledge in a variety of research fields to be of the highest international class. In particular, the Jury cites his brilliant and uniquely important studies on the microbial loop which

have opened up a fundamentally new research field. Professor Fenchel is, in addition, an excellent publicizer in his field of research with authorship of a number of standard works in marine ecology.

Marine Ecology Jury ECI:

Professor John S. Gray, Oslo, Norway (Chairman) Professor Ernest Naylor, Bangor, Wales, UK Professor Hans-Peter Bulnheim, Hamburg, FRG Dr. Trevor Platt, Dartmouth, N.S., Canada Professor John D. Costlow, Beaufort, N.C., USA Dr T. S. S. Rao, Dona Paula, Goa, India Dr. Nicolas S. Fisher, Upton, N.Y., USA

\section{ECOLOGY INSTITUTE}

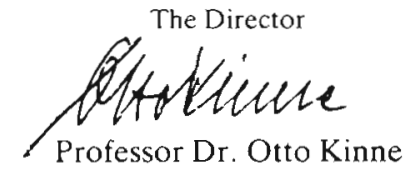

Oldendorf/Luhe, Federal Republic of Germany, July 9, 1986 


\section{ECOLOGY INSTITUTE IRPE PRIZE 1986}

\section{Dr. Colleen Cavanaugh}

has been elected by the Marine Ecology Jury of the Ecology Institute (ECI) as the winner of the

\section{IRPE PRIZE}

\section{(International Recognition of Professional Excellence)}

The Jury found the research of Dr. C. Cavanaugh on chemosynthesis initially concerning hot-vent fauna but extended to other sulphide-rich

habitats - to be highly original and to represent a major scientific breakthrough. Her hypothesis, formulated whilst a beginning graduate student, met severe opposition from established scientists with opposing views, but nevertheless proved to be correct. The Jury acknowledge Dr. Cavanaugh's brilliant and independent research in understanding chemosynthetic energetic pathways.

\section{Marine Ecology Jury ECI:}

Professor John S. Gray, Oslo, Norway (Chairman) Professor Ernest Naylor, Bangor, Wales, UK Professor Hans-Peter Bulnheim, Hamburg, FRG Dr Trevor Platt, Dartmouth, N.S., Canada Professor John D. Costlow, Beaufort, N.C., USA Dr T. S. S. Rao, Goa, India Dr. Nicolas S. Fisher, Upton. N.Y., USA

\section{ECOLOGY INSTITUTE}

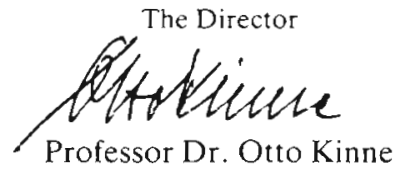

Oldendorf/Luhe, Federal Republic of Germany, July 9, 1986

Fig. 2. IRPE PRIZE in marine ecology 1986: Reproduction of ECI's formal citation. Dr Colleen Cavanaugh is presently Postdoctoral Fellow at The Marine Laboratories, Harvard University, Cambridge, Massachusetts, USA. 
Challenging established concepts, her hypothesis proved to be correct and significantly advanced our knowledge on chemosynthetic energy pathways. Colleen Cavanaugh's ECI citation appears in Fig. 2; a laudatio by John Gray, on p. 9.

I thank the Marine Ecology Jury most sincerely for their judicious, impartial and successful work in selecting the Prize Winners 1986.

\section{ECI STAFF 1986}

The scientific staff of the Ecology Institute comprises 3 groups of ecologists - marine, terrestrial, and limnetic - all of high international reputation. Scientific staff members serve for a period of 6 yr. Reappointment is possible. Neither the Director nor any of the scientific staff receives remuneration.

\section{Scientific staff}

Director: Professor Dr. Otto Kinne, Oldendorf/Luhe, FRG

\section{Marine Ecology}

Dr. F. Azam, La Jolla, USA

Prof. Dr. H.-P. Bulnheim, Hamburg, FRG

Prof. J. D. Costlow, Beaufort, USA

Prof. T. Fenchel, Aarhus, Denmark

Dr. N. S. Fisher, Upton, USA

Prof. J. Gray, Oslo, Norway

Prof. E. Naylor, Bangor, UK

Dr. T. Platt, Dartmouth, Canada

Prof. G. G. Polikarpov, Sevastopol, USSR

Prof. L. R. Pomeroy, Athens, USA

Dr. T. S. S. Rao, Dona Paula, India

Prof. A. V. Zhirmunsky, Vladivostok, USSR (invited)

\section{Editorial stafi}

J. Austin

R. Friedrich

T. Galvin

\section{Terrestrial Ecology}

Prof. T. N. Ananthakrishnan, Madras, India

Dr. T. Chapin, Fairbanks, USA

Prof. J. Ehleringer, Salt Lake City, USA

Prof. M. Gadgil, Bangalore, India

Prof. W. Hamilton, Oxford, UK (invited)

Prof. J. L. Harper, Bangor, UK

Prof. E. Kuno, Kyoto, Japan

Prof. A. Macfayden, Coleraine, UK

Prof. H. Remmert, Marburg, FRG

Academician Prof. V. E. Sokolov, Moscow, USSR

Dr. Sir R. Southwood, Oxford, UK

Prof. S. Ulfstrand, Uppsala, Sweden

\section{Limnetic Ecology}

Prof. J. I. Furtado, London, UK Prof. S. D. Gerking, Tempe, USA

Prof. J. E. Hobbie, Woods Hole, USA

Prof. K. Lillelund, Hamburg, FRG

Prof. R. Margalef, Barcelona, Spain

Prof. J. Overbeck, Plön, FRG

Prof, T. J. Pandian, Madurai, India

Prof. T. B. Reynoldson, Bangor, UK

Prof. L. A. Sirenko, Kiev, USSR (invited)

Prof. G. G. Vinberg, Leningrad, USSR (invited)

Prof. W. D. Williams, Adelaide, Australia

\section{Technical staff}

G. Bendler

I. von Capelle

B. Eggers

H. Kinne

H. Witt 